\title{
Variability of VTEC Gradient and TEC Rate Index Over Kisumu, Kenya During Selected Quiet and Storm Days of 2013 and 2014
}

\author{
Uluma Edward ${ }^{1}$, Ndinya Boniface ${ }^{1, ~ *}$, Omondi George ${ }^{2}$ \\ ${ }^{1}$ Department of Physics, Masinde Muliro University of Science \& Technology, Kakamega, Kenya \\ ${ }^{2}$ Department of Physics and Materials Science, Maseno University, Maseno, Kenya
}

\section{Email address:}

nyogesa_edward@yahoo.com (N. Boniface)

*Corresponding author

\section{To cite this article:}

Uluma Edward, Ndinya Boniface, Omondi George. Variability of VTEC Gradient and TEC Rate Index Over Kisumu, Kenya During Selected Quiet and Storm Days of 2013 and 2014. American Journal of Astronomy and Astrophysics. Vol. 7, No. 4, 2019, pp. 67-72. doi: 10.11648/j.ajaa.20190704.13

Received: October 30, 2019; Accepted: November 26, 2019; Published: December 4, 2019

\begin{abstract}
Vertical Total electron content (VTEC) gradient or rate of change of TEC (ROT) and total electron content (TEC) rate index or rate of change of TEC index (ROTI) can directly be estimated from receiver independent exchange (RINEX) data and can be used to estimate presence and intensity of ionospheric irregularities. In this paper we present results of the variation of ROT and ROTI over Kisumu, Kenya (Geomagnetic coordinates: $9.64^{\circ} \mathrm{S}, 108.59^{\circ} \mathrm{E}$; Geographic coordinates: $0.02^{\circ} \mathrm{S}$, $34.6^{\circ} \mathrm{E}$ ) for both selected quiet and disturbed conditions between $1^{\text {st }}$ January 2013 and $31^{\text {st }}$ December 2014 using data derived from NovAtel GSV4004B SCINDA-GPS receiver at Kisumu as a step in establishing ionospheric irregularities over Kisumu, Kenya during a high solar activity period of solar cycle 24 . ROT was calculated from filtered average daily VTEC data within intervals of 120 seconds while ROTI was computed over 4 minutes window from ROT. ROT and corresponding ROTI for the selected quiet and storm days were plotted against universal time (UT). The presence and intensity of irregularities on the selected quiet and storm days of the years 2013 and 2014 were determined by checking ROT fluctuations and the corresponding ROTI values from the plots. The obtained results showed increased fluctuation of ROT corresponding with large ROTI values after sunset. The selected storm days of the years 2013 and 2014 had higher ROTI values than the selected quiet days of the years 2013 and 2014. The higher ROTI values during the selected storm days may be attributed to the impact of geomagnetic storms brought about by several competing dynamics including Prompt penetration electric field (PPEF), disturbance dynamo electric field (DDEF) and reduction in electron density due to increased recombination rates. The high ROTI values after sunset were a manifestation of post-sunset plasma irregularities. The obtained results also showed a diurnal trend for ROT and ROTI where ROT increased steadily from 0.00UT to around 12:00UT before falling and having an increased fluctuation between 18:00UT and 20:00UT. This corresponded well with low ROTI values between 0:00UT and 16:00UT followed by high ROTI values between 18:00UT and 20:00UT. The diurnal variability of ROT might have resulted from variation of TEC and which was attributed to changes in the intensity of incoming solar radiation.
\end{abstract}

Keywords: Ionospheric Irregularities, Total Electron Content, Geomagnetic Storms

\section{Introduction}

Ionospheric irregularities caused by fluctuation in total electron content (TEC) $[1,2]$ pose threats to Global positioning systems (GPS) manifested in signal loss [3, 4]. The occurrence of the irregularities depends on local time, season, latitude, solar cycle and magnetic activity [5-7].
Irregularities commonly occur around the equatorial ionization anomaly region where highest TEC gradients are attained. These large TEC gradient leads to increased ROT fluctuation and high ROTI values after sunset [8]. Geomagnetically disturbed days are also strongly affected by irregularities [7]. This is due to the competing effects of prompt penetration electric fields (PPEF), disturbance 
dynamo electric fields (DDEF) and storm winds [9-12]. These irregularities have been studied using different techniques including global positioning system (GPS). Studies done by [8] using ground based GPS receivers around dip equator from the year 2000 to 2006 indicated that plasma irregularities caused TEC depletions, increased ROT fluctuations and high ROTI values between sunset and midnight for all satellites. [13] Used ROTI based on the ROT within a period of 5 minutes to detect plasma bubbles using TEC data gathered from 3 equatorial ground based GPS stations and 3 low latitude ground based GPS stations. [14] Studied the variability of ROTI and VTEC. They used ROTI as indicator of ionospheric scintillation for the impact of very high-speed solar wind stream in the low and middle latitude ionosphere. They observed that the arrival of Coronal mass ejections (CMEs) led to an increase in VTEC depletion, hence high ROTI which then decreased after the impact. They attributed the increase in VTEC depletion to the physical process of PPEF and a reduction in VTEC to DDEF. [15] Characterized ionospheric irregularities at different longitudes during disturbed and quiet geomagnetic conditions in March 2015. They observed that geomagnetic storms did not inhibit the development of irregularities in all the stations under study in the American sector. However in the African sector, the storm appeared to hinder development of irregularities during storm days in all stations. This was attributed to differences in storm timing and the effects of PPEF and DDEF. This paper aims to investigate the variability of ROT and ROTI for selected quiet and storm days of the year 2013 and 2014 which was a high solar activity period of solar cycle 24 .

\section{Materials and Methods}

RINEX data archived in the Scintillation Index Decision Aid (SCINDA) between $1^{\text {st }}$ January 2013 and $31^{\text {st }}$ December 2014 was downloaded from the SCINDA-GPS receiver. The obtained RINEX data was unzipped using the WinRAR program and processed using Gopi Software to obtain VTEC and UT in a ten column daily file of ionospheric observables.

To reduce multipath effects, the selected data was of elevation angles of $40^{\circ}$ and above. The filtered average daily data of VTEC and UT were obtained and used to generate ROT and ROTI. The selected quiet days and disturbed days for 2013 and 2014 period of study were obtained from Dst index using data obtained from the link: www.wdc.kug.kyotoua.ac.jp/dstdir. The quiet days considered were days having Dst values $>-25 \mathrm{nT}$ while storm days were days having Dst values $\leq-50 \mathrm{nT}$. The level of geomagnetic activity for the selected quiet and storm days was selected using the $\mathrm{Kp}$ index obtained from the link: www.kugi.kyoto-ua.ac.jp/kp, where the selected quiet days had $\mathrm{Kp}$ values between 0 and 2 while the selected storm days had Kp values between 3 and 9.

ROT was calculated directly from the filtered average daily VTEC data within intervals of 120 seconds using equation (1) [16],

$$
R O T=\frac{T E C_{t}-T E C_{t-1}}{\Delta t}
$$

where,

$\mathrm{t}$ and $\mathrm{t}-1=$ time difference between the epochs in minute

ROTI was computed over 4 minutes window using measurements of ROT using equation (2).

$$
R O T I=\sqrt{\left\langle R O T^{2}\right\rangle-\langle R O T\rangle^{2}}
$$

Using MATLAB, we plotted ROT as indicated in Figures 1 (a), 1 (c), 1 (e), 1 (g), 2 (a), 2 (c), 2 (e), 2 (g), 3 (a), 3 (c), 3 (e), 3 (g), 4 (a), 4 (c), 4 (e) and 4 (g) and the corresponding ROTI plots as indicated in Figures 1 (b), 1 (d), 1 (f), 1 (h), 2 (b), 2 (d), 2 (f), 2 (h), 3 (b), 3 (d), 3 (f), 3 (h), 4 (b), 4 (d), 4 (f) and 4 (h) against universal time for the selected quiet and storm days of the year 2013 and 2014. The ROT and ROTI plots were used to compare ROT and the corresponding ROTI for each of the selected quiet and storm days of the years 2013 and 2014.

\section{Results}

\subsection{Variability of ROT and ROTI for Selected Quiet Days of 2013}
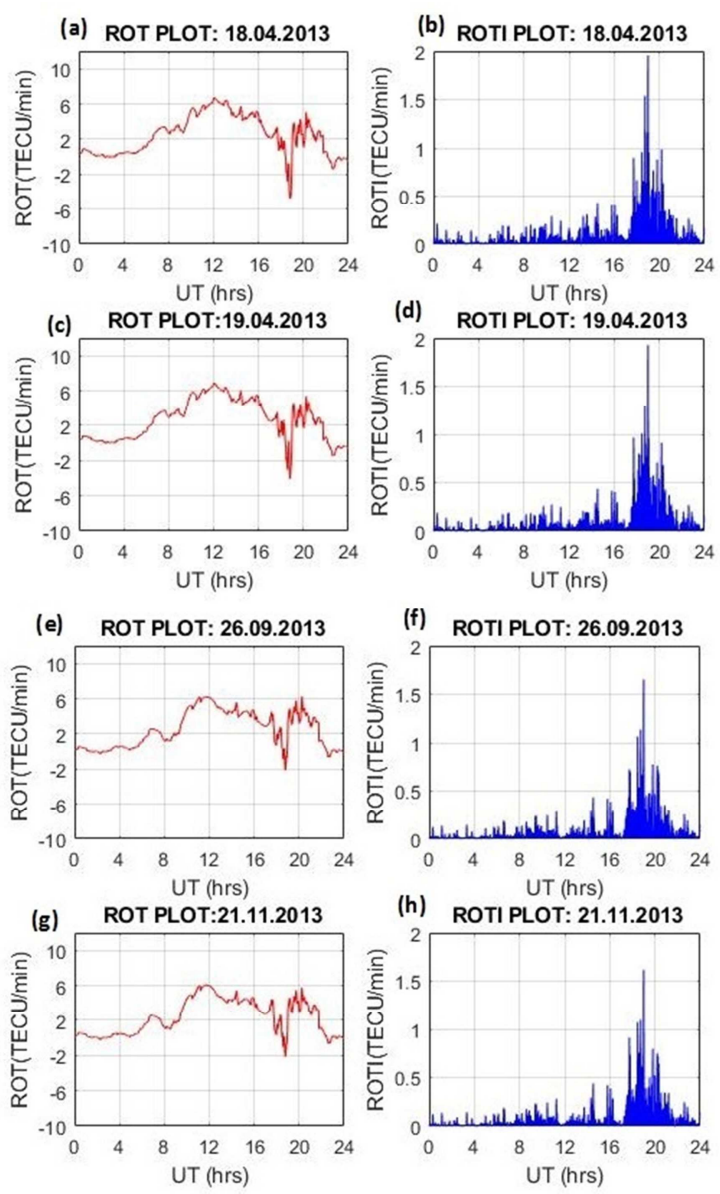

Figure 1. ROT and ROTI plots for $18^{\text {th }}$ April 2013, $19^{\text {th }}$ April 2013, $26^{\text {th }}$ September 2013 and $21^{\text {st }}$ November 2013. 
Figure 1 shows ROT and ROTI plots for selected quiet days of the year 2013 .

Figures 1 (a) and 1 (c) shows a steady rise in ROT from 04:00UT and reached its maximum at about 12:00UT before beginning to decrease up to 18:00UT. An increased ROT fluctuation was observed between 18:00 and 20:00UT before beginning to decline again. There was a corresponding slight rise in ROTI values from 0:00UT to about 17:00UT as indicated in Figures 1 (b) and 1 (d). High ROTI values of about 1.9 TECU/min were attained between 18:00UT and 20:00UT for both $18^{\text {th }}$ April 2013 and $19^{\text {th }}$ April 2013 as indicated in Figures 1 (b) and 1 (d).

Figures $1(\mathrm{e})$ and $1(\mathrm{~g})$ shows a steady rise in ROT from 04:00-07:00UT, a slight fall from 07:00-08:00 UT followed by a rise, reaching its maximum at about 12:00UT before beginning to decrease up to $18: 00 \mathrm{UT}$ for $26^{\text {th }}$ September 2013 and $21^{\text {st }}$ November 2013. An increased ROT fluctuation was observed at between 18:00 and 20:00UT. There was a corresponding slight rise in ROTI values from 0:00UT to about 17:00UT. High ROTI values of about $1.7 \mathrm{TECU} / \mathrm{min}$ and 1.6 TECU/min were attained between 18:00UT and 20:00UT as indicated in Figures 1 (f) and 1 (h) respectively.

\subsection{Variability of ROT and ROTI for Selected Quiet Days of 2014}

Figure 2 shows ROT and ROTI plots for selected quiet days of the year 2014.

Figures 2 (a), 2 (c), 2 (e) and 2 (g) shows a steady rise in ROT from 04:00-07:00UT, a slight fall from 07:00-08:00 UT followed by a rise, reaching its maximum at about 12:00UT before beginning to decrease up to 18:00UT for $16^{\text {th }}$ April 2014, $13^{\text {th }}$ May 2014, 26 ${ }^{\text {th }}$ August 2014 and $7^{\text {th }}$ October 2014 respectively. An increased ROT fluctuation was observed between 18:00 and 20:00UT as indicated in the Figures 2 (a), 2 (c), 2 (e) and 2 (g).

There was a corresponding slight rise in ROTI values from 0:00UT to about 17:00UT. High ROTI values were attained between 18:00UT and 20:00UT. That is $1.7 \mathrm{TECU} / \mathrm{min}$ for $16^{\text {th }}$ April 2014 as indicated in Figure 2 (b), 1.6 TECU/min for $13^{\text {th }}$ May 2014 as indicated in Figure 2 (d), 1.6 TECU/min for $26^{\text {th }}$ August 2014 as indicated in Figure 2 (f) and $1.7 \mathrm{TECU} / \mathrm{min}$ for $7^{\text {th }}$ October 2014 as indicated in Figure 2 (h).

It is important to note that during the selected quiet days shown in Figures 1 and 2, increased ROT fluctuations occurred between 18:00UT and 20:00UT and it corresponded with high ROTI values. The largest high ROTI value attained was $1.9 \mathrm{TECU} / \mathrm{min}$ on $18^{\text {th }}$ April 2013 and $19^{\text {th }}$ April 2013 as indicated in Figures 1 (b) and 1 (d) respectively while the lowest high ROTI value attained was $1.6 \mathrm{TECU} / \mathrm{min}$ on $21^{\text {st }}$ November 2013, $13^{\text {th }}$ May 2014 and $26^{\text {th }}$ August 2014 as indicated in Figures 1 (h), 2 (d) and 2 (f) respectively.
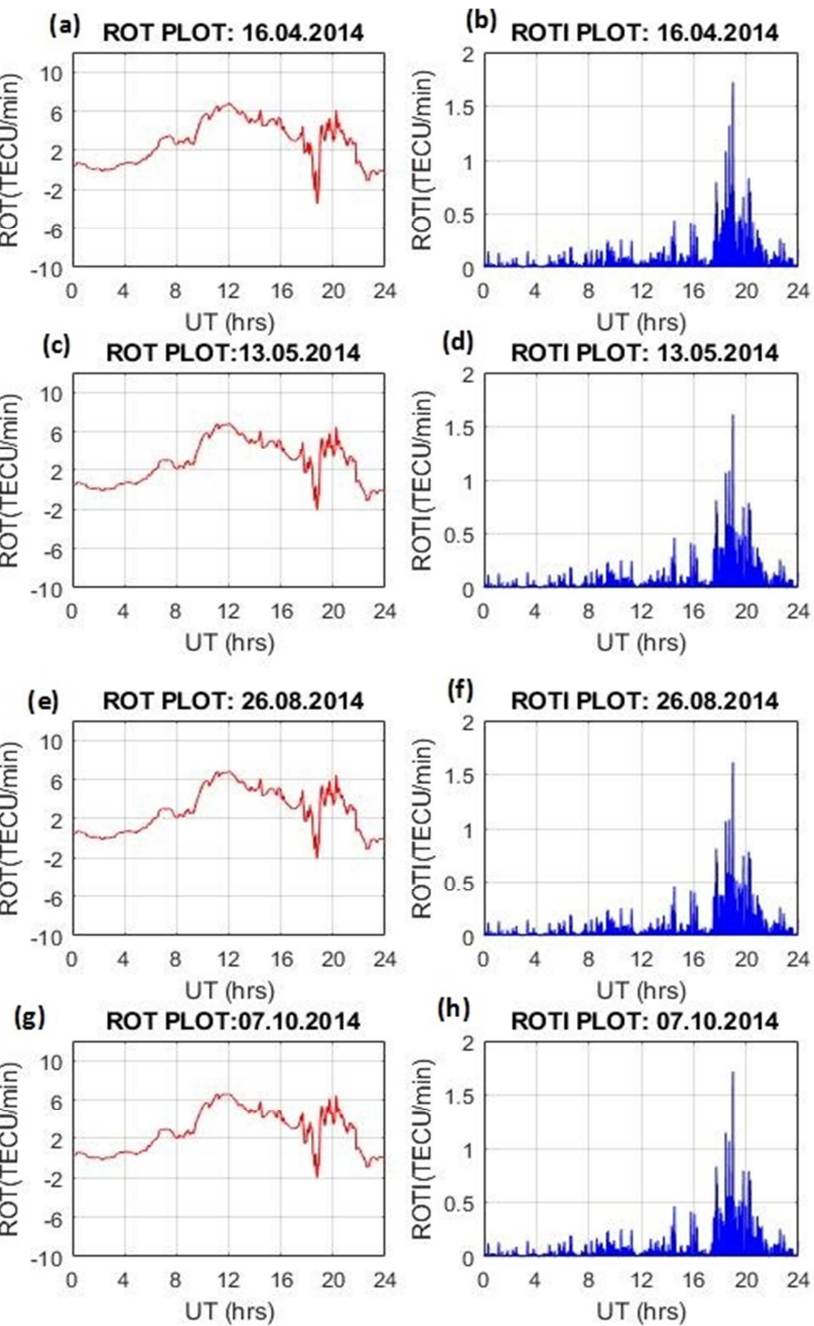

Figure 2. ROT and ROTI plot for $16^{\text {th }}$ April 2014, $13^{\text {th }}$ May 2014, 26 $6^{\text {th }}$ August 2014 and $7^{\text {th }}$ October 2014.

\subsection{Variability of ROT and ROTI for Selected Storm Days of 2013}

Figure 3 shows ROT and ROTI plots for selected storm days of the year 2013 .

Figures 3 (a), 3 (c), 3 (e) and 3 (g) shows a steady rise in ROT from 04:00-07:00UT, a slight fall from 07:00-08:00 UT followed by a rise, reaching its maximum at about 12:00UT before beginning to decrease up to 18:00UT for $24^{\text {th }}$ April 2013, 1st May 2013, $9^{\text {th }}$ November 2013 and $11^{\text {th }}$ November 2013 respectively. An increased ROT fluctuation was observed at between 18:00 and 20:00UT. There was a corresponding slight rise in ROTI values from 0:00UT to about 17:00UT. High ROTI values of about $1.6 \mathrm{TECU} / \mathrm{min}$ were attained for $24^{\text {th }}$ April 2013 as indicated in Figure 3 (b), $1.7 \mathrm{TECU} / \mathrm{min}$ for $1^{\text {st }}$ May 2013 as indicated in Figure 3 (d), $2.4 \mathrm{TECU} / \mathrm{min}$ on $9^{\text {th }}$ November 2013 as indicated in Figure 3 (f) and $2.3 \mathrm{TECU} / \mathrm{min}$ for $11^{\text {th }}$ November 2013 as indicated in Figure 3 (h) between 18:00UT and 20:00UT. 
(a) ROT PLOT: 24.04.2013

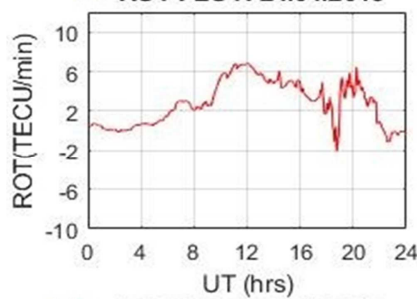

(c) ROT PLOT:01.05.2013

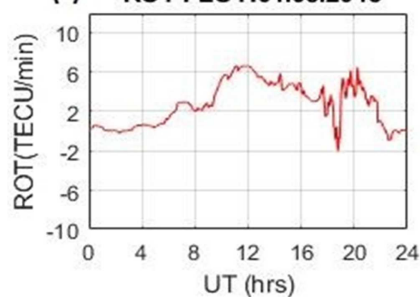

(e) ROT PLOT: 09.11.2013

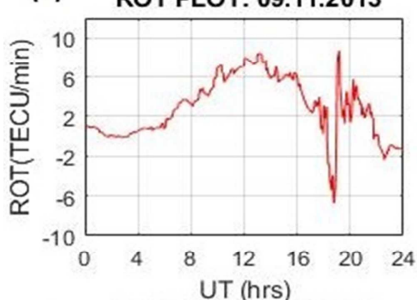

(g) ROT PLOT:11.11.2013

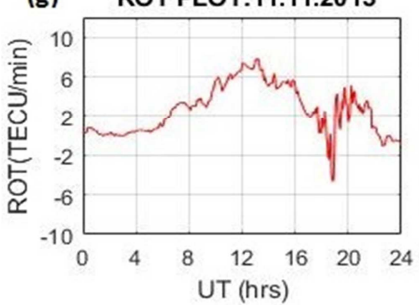

(b) ROTI PLOT: 24.04.2013

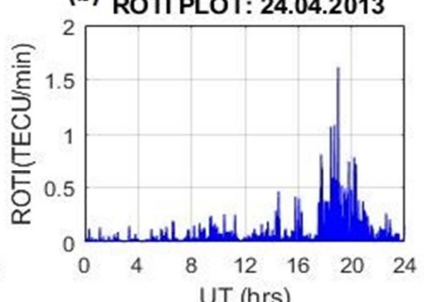

(d) ROTI PLOT: 01.05.2013
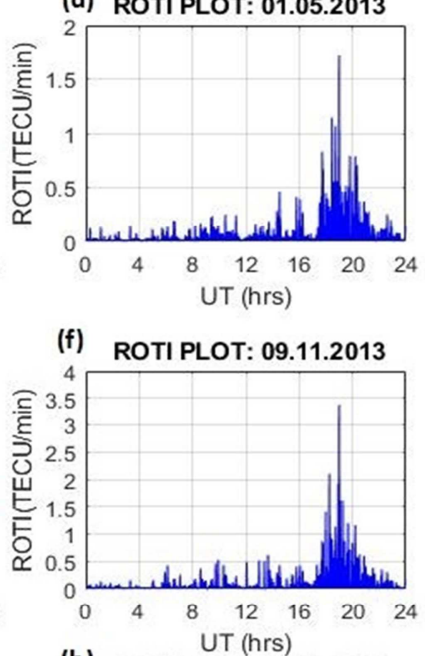

(h) ROTI PLOT: 11.11.2013

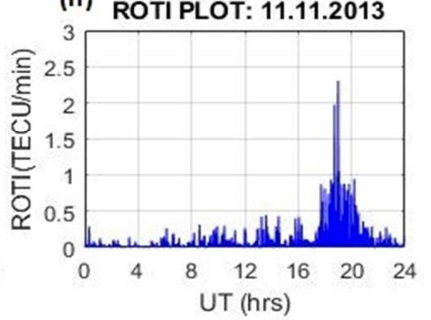

Figure 3. ROT and ROTI plots for $24^{\text {th }}$ April 2013, $1^{\text {st }}$ May 2013, $9^{\text {th }}$ November 2013 and $11^{\text {th }}$ November 2013.

\subsection{Variability of ROT and ROTI for Selected Storm Days of 2014}

Figure 4 shows ROT and ROTI plots for selected storm days of the year 2014 .

Figures 4 (a), 4 (c), 4 (e) and 4 (g) shows a steady rise in ROT from 04:00UT and reached its maximum at about 13:00-15:00UT before beginning to decrease up to 18:00UT for $1^{\text {st }}$ March 2014, $12^{\text {th }}$ April 2014, $28^{\text {th }}$ August 2014 and $10^{\text {th }}$ November 2014 respectively. An increased ROT fluctuation was observed at between 18:00 and 20:00UT. There was a corresponding slight rise in ROTI values from 0:00UT to about 17:00UT as indicated in Figures 4 (b), 4 (d), 4 (f) and 4 (h). High ROTI values of about $3.4 \mathrm{TECU} / \mathrm{min}$ on $1^{\text {st }}$ March 2014, 2.3 TECU/min on $12^{\text {th }}$ April 2014, 1.4 TECU/min on $28^{\text {th }}$ August 2014 and $1.6 \mathrm{TECU} / \mathrm{min}$ on $10^{\text {th }}$ November 2014 were attained between 18:00UT and 20:00UT as indicated in Figures 4 (b), 4 (d), 4 (f) and 4 (h) respectively.

Just like the selected quiet days of the years 2013 and 2014, the selected storm days of the years 2013 and 2014 were noticed to have increased ROT fluctuations between 18:00UT and 20:00UT and they corresponded well with high

ROTI values. Largest high ROTI value of $3.4 \mathrm{TECU} / \mathrm{min}$ were attained on $9^{\text {th }}$ November 2013 and $1^{\text {st }}$ March 2014 as indicated in Figures 3 (f) and 4 (b) respectively while the smallest high ROTI value of $1.4 \mathrm{TECU} / \mathrm{min}$ was attained on $28^{\text {th }}$ August 2014 as indicated in Figure 4 (f).

(a) ROT PLOT: 01.03.2014

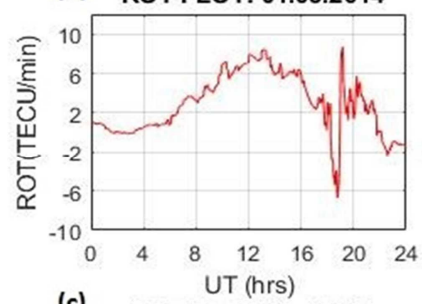

(c) ROT PLOT:12.4.2014

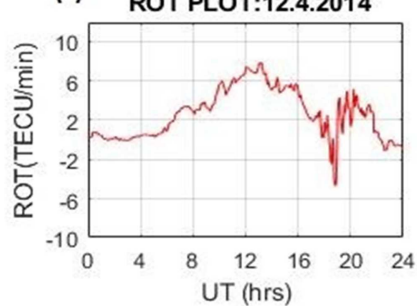

(e) ROT PLOT: 28.08.2014

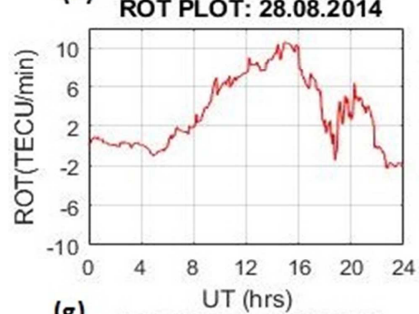

(g) ROT PLOT:10.11.2014

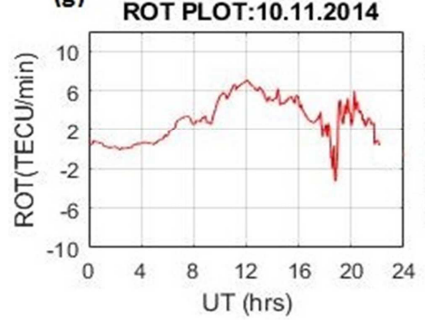

Figure 4. ROT and ROTI plots for $1^{\text {st }}$ March 2014, $12^{\text {th }}$ April 2014, $28^{\text {th }}$ August 2014 and $10^{\text {th }}$ November 2014.

\section{Discussion}

Generally, the selected quiet and storm days of the years 2013 and 2014 displayed an almost similar diurnal trend for both ROT and ROTI where ROT rose steadily from 0:00UT and attained maximum values between 12:00UT and 14:00UT. Increased fluctuation of ROT was observed between 18:00UT and 20:00UT. These corresponded with low ROTI values from 0:00UT-16:00UT followed by very high ROTI values between 18:00UT and 20:00UT as indicated in Figures 1, 2, 3 and 4. The diurnal variability of ROT and ROTI might have resulted from variation of VTEC and which was attributed to changes in the intensity of incoming solar radiation [17]. High solar intensity leads to increased ionization hence high VTEC while low solar intensity leads to reduced ionization leading low VTEC [15]. 
This diurnal trend was also observed by [8] where ROTI was low and constant during the day and night on some days and low and constant during the day and larger after sunset. In this study, increased fluctuation of ROT was seen to correspond with high ROTI values after sunset (18:0020:00UT) for the both selected quiet and storm days of the years 2013 and 2014. This might have resulted from electron density depletions which arise after sunset when the eastward electric field is enhanced. This intensifies the upward plasma drift to higher altitudes. The plasma density irregularities are therefore generated as a result of a generalized nonlinear Rayleigh-Taylor and E x B instabilities [19, 20]. The high ROTI values being observed several hours after sunset might be attributed to background electron density persisting for several hours after sunset. We might also attribute this to the neutral winds dynamo which is driven by E-region neutral winds which are usually generated by convection and flow from west to east in the evening in Kenya [21]. Theses Eregion neutral winds leads to production of electric field enhancement [22]. These results are similar to those reported by [8]. The selected storm days of the years 2013 and 2014 exhibited higher ROTI values (about $3.4 \mathrm{TECU} / \mathrm{min}$ ) as indicated in Figures 3 (f) and 4 (b) than the selected quiet days of 2013 and 2014 (about 1.9 TECU/min) as indicated in Figures 1 (b) and 1 (d) between 18:00UT and 20:00UT. These results indicate that irregularity levels were higher during storm period and lower during quiet period after sunset. The higher ROTI values during selected storm days of the years 2013 and 2014 reflected the ionospheric TEC response to geomagnetic storms, since during geomagnetically disturbed periods the ionospheric behaviour is controlled by several competing dynamics including PPEF, DDEF and reduction in electron density due to increased recombination rates. A similar case was reported by [14] in their study on the daily variability of ROTI and VTEC in October 2012. PPEF which are usually 'short-lived' perturbations taking few hours affect low-latitude ionosphere by producing plasma drift perturbations and change in ionization density [23] while DDEF [9] which is a long lasting perturbation taking several hours originate from highlatitude ionosphere and moves towards middle and low latitude ionospheres leading to variation in ionization density. During storm days, strong eastward electric fields emanating from the magnetosphere during the day increases the upward plasma drift which promotes irregularity formation which is observed in high ROTI values after sunset. In this study, the large high ROTI values after sunset therefore implied intense irregularities while small high ROTI values implied reduced irregularities in the ionosphere during that time.

\section{Conclusion}

The variability of ROT and ROTI over Kisumu, Kenya for selected quiet and storm days of the year 2013 and 2014 has been investigated and it has been found that the selected quiet and storm days of the years 2013 and 2014 displayed a relatively consistent diurnal variation of ROT and ROTI where ROT underwent a steady rise from 04:00UT to 07:00UT and attained maximum value at around 12:00UT before beginning to decrease up to 18:00UT. An increased ROT fluctuation was observed between 18:00 and 20:00UT. There was a corresponding slight rise in ROTI values until 18:00UT where high ROTI values were attained between 18:00-20:00UT. The diurnal variability of ROT and ROTI resulted from variations of VTEC which was attributed to the changes in solar intensity during different hours of the day. The selected storm days of the years 2013 and 2014 had higher ROTI values as compared to the ROTI values for the selected quiet days of the years 2013 and 2014 between 18:00 and 20:00UT (after sunset). The higher ROTI values during the selected storm days of the years 2013 and 2014 were attributed to the ionospheric TEC response to geomagnetic storms. The obtained results show that irregularities develop mostly after sunset hours during both geomagnetically quiet and geomagnetically disturbed conditions, with disturbed conditions having more intense irregularities than quiet conditions over Kisumu, Kenya which is situated in the equatorial region.

\section{Acknowledgements}

We are very grateful to Boston College and the Air Force Research Laboratory (AFRL), USA who supplied the Kisumu SCINDA-GPS receiver at Maseno University that we used to access data. We are also grateful to Masinde Muliro University of Science and Technology (MMUST) for providing library facilities when undertaking the research.

\section{References}

[1] Fayose, R. S., Oladosu, O. R., Rabiu, A. B. and Grooves, K. (2012). Variation of Total Electron Content (TEC) and their Effect on GNSS over Akure, Nigeria. doi: 10.5539/apr.v4n2p105. https://dx.doi.org/10.5539/apr.v4n2p105.

[2] Ndeda, O. H., and Odera, P. O. (2014). Analysis of Longitudinal Advancement of the peak Total Electron Content in the African equatorial anomaly region using data from GPS receivers and GIS stations in Kenya, Canadian centre of Sc. \& Educ. Applied Phys. Research: vol. 6, No. 1; 2014. Doi: 10.5539/apr.V6n.1p.19.

[3] Kintner, P. M., Ledvina, B. M., De paula, (2007). GPS and ionospheric scintillations. Space Weather 5, S09003. https://doi.org/10.1029/2006SW000260.

[4] Prikryl, P., Jayachandran, T., Mushini, S., Richardson, I. (2014). High-latitude GPS phase scintillation and cycle slips during high-speed solar wind streams and interplanetary coronal mass ejections: a superposed epoch analysis. Earth, planets space 66: 62, doi: 10.1186/18805981-66-62.

[5] Woodman, R. F. and LaHoz, C. (1976). Radar observations of $\mathrm{F}$ region equatorial irregularities. J, Geophys. Res, 81, 5447 .

[6] Basu, Su, Basu, S. (1985). Equatorial scintillations: advances since ISEA-6. J. Atmos. Terr. phys. 47 (8), 753-768. 
[7] Muella, M. T. A. H., de Paula, E. R., Kantor, I. J., Rezende, L. F. G., Smorigo, P. RF. (2009). Occurrence and zonal drifts of small-scale ionospheric irregularities over an equatorial station during solar maximum-magnetic quiet and disturbed conditions. AdvSpace Res. 43, 957-1973.

[8] Nishioka, M., Saito, A., Takano T. and Tsugawa T. (2008). Occurrence characteristics of plasma derived from globalground based GPS receiver networks. J. Geophys, Res., 113, A05301, doi: 10.1029/2007JA012605.

[9] Blanc, M. and Richmomd A. D. (1980). The ionospheric disturbance dynamo. J Geophys Res 85: 1669-1686.

[10] Abdu, M. A., de Paula, E. R., Batista, I. S., Reinish, B. W., Matsuoka, M. T., Carmago, P. O., Veliz, O., Denardini, C. M., Sobral J. H. A., Kherani, E. A., de Siquera, P. M. (2008). Abnormal evening vertical plasma drifts and effects on ESF and EIA over Brazil-South Atlantic sector during 30th October 2003 superstorm. J Geophys Res. 113: A07313. https://doi.org/1029/2007JAD12844.

[11] de Siqueira Negreti, P. M., de Paula, E. R., Candido, C. M. N. (2017). Total electron content responses to HILDCAAs and geomagnetic storms over South America. Ann. Geophys., 35, 1309-1327, 2017. https://doi.org/10.5194/angeo-351309,2017

[12] Bhattacharrya, A., Fedrizzi, M., \& Fuller-Rowell, T. J., Gurram, P., Kakad, B., Sripathi, S. and Sunda, S. (2019). Effect of magnetic related storm thermospheric changes on eveolution of equatorial plasma bubbles. Journal of Geophysical Researc, space physics, 124, 2256-2270. https://doi.org/10.1029/2018JA02595.

[13] Li, G., Ning, B., Wan, W. and Zhao, B. (2006). Observations of GPS ionospheric scintillations over Wuhan during geomagnetic storms. Ann Geophys 24: 1581-1590. https://doi.org/105194, Angeo-24-1581-2006.

[14] Azzouzi, I., Migoya-Orue, Y., Coisson, P., Amory Mazaudier, C., Fleury, R. and Radicella, S. M. (2016). Day to day variability of VTEC and ROTI in October 2012 with impact of high-speed solar wind stream on $13^{\text {th }}$ October 2012. www.researchgate.net/publication/299470637.
[15] Bolaji, O. S., Adebiyi, S. J. and Fashae J. B. (2019). Characterization of ionospheric irregularities at different longitudes during quiet and disturbed geomagnetic conditions. Journal of Atmospheric and Solar-terrestrial physics. https://doi.org/10.1016/j.jastp.2018.11.007.

[16] Pi, X, Mannucci, A. J., Lindquister, U. J. and HO, C. M. (1997). Monitoring of Global Ionospheric irreqularities using the worldwide GPS network. Geophys. Res. Lett, 24 (18), 2283-2286, 1997. Doi: 10.1029/97GLO2273.

[17] Modi, R. P. and Iyer, K. N. (1989). IEC and slab thickness near the peak of equatorial anomaly during sunspot maximum and minimum. Indian Journal of Radio and space physics, 18, 23-26.

[18] Bolaji, O. S., Adeniyi, J. O., Radicella, S. M. and Doherty, P. H. (2012). Variability of total electron content over an equatorial West African station during low solar activity, Radio Sci., $47, \quad$ RS1001, https://doi.org/10.1029/2011RS004812.

[19] Fejer, B. G., Scherlies, L. and De paula, E. R. (1999). J. Geophys. Res. 104,19859. https://dx.doi.org/10.1029/1999JA900271.

[20] Meggs, R. W., Mitchell, C. N. and Honary, F. (2008). GPS Solut. 12, 281. https:/dx.doi.org/10.1007/sh10291-008-00903.

[21] Mukabana, J. R. and Pielke, R. A. (1996). Investigating the influence of synoptic-scale Monsoonal Winds and Mesoscale circulations on Diurnal weather patterns over Kenya using numerical Model, American Meteorological Society, Monthly Weather Review vol. 124.

[22] Omondi, G., Ndinya, B. and Baki, P. (2014). A study of the Equatorial Ionosphere over Nairobi During selected magnetically disturbed and quiet times for the year 2009 Using co-located instruments. IJARPS, Vol. 1, 18-26, ISSN 2349-782.

[23] Nishida, A., Iwasaki, N. and Nadata, T. (1996). The origin of fluctuations in the equatorial electrojet: a new type of geomagnetic variation, Ann. Geophys., Res., Vol. 113, A05301. 